\title{
A rare cause of short stature: Kenny-Caffey syndrome type 2 - a case report and literature review
}

\author{
Dagmara Kaleta ${ }^{1}$, Paweł Zapolnik², Anna Mazur ${ }^{3}$, Antoni Pyrkosz ${ }^{4}$ \\ 'Department of Paediatrics, Paediatric Endocrinology, and Diabetes, Medical College, University of Rzeszów, Rzeszów, Poland \\ ${ }^{2}$ Students' Scientific Association of Clinical Genetics, Department of Clinical Genetics, Medical College, University of Rzeszów, \\ Rzeszów, Poland \\ ${ }^{3}$ Students' Scientific Association of Paediatrics, Department of Paediatrics, Medical College, University of Rzeszów, Rzeszów, \\ Poland \\ ${ }^{4}$ Department of Clinical Genetics, Medical College, University of Rzeszów, Rzeszów, Poland
}

\section{ABSTRACT}

Kenny-Caffey syndrome type 2 is a very rare disease characterized by short stature, skeleton and eye abnormalities, hypoparathyroidism, hypocalcemia, and normal intellectual development. It is caused by a mutation in the FAM111A gene and inherited in an autosomal dominant way. It occurs at a frequency of 1:1000 000. Less than 100 cases had been described to date. Treatment in this disease is only symptomatic and the use of growth hormone does not give satisfying effects. We present a case of a 12-year-old boy with short stature, hypoparathyroidism, hypothyroidism, and hyperopia. The next-generation sequencing study revealed a mutation $(\mathrm{R} 569 \mathrm{H})$ in one allele of the above-mentioned gene. On the basis of the clinical picture and special investigations results, Kenny-Caffey syndrome type 2 was diagnosed.

\section{KEY WORDS:}

hypothyroidism, hypoparathyroidism, hypocalcaemia.

\section{INTRODUCTION}

Kenny-Caffey syndrome type 2 is an extremely rare autosomal dominant genetic disorder characterized by short stature, hypoparathyroidism, and abnormalities affecting the skeleton and the eyes, which may occur even in the infancy period. Intellectual development is normal. Currently, treatment is directed towards specific symptoms and countermeasures of distant disease effects [1]. The aim of this study is to draw attention to this rare disease, and to present a clinical approach that may help physicians in diagnosing patients.

\section{CASE REPORT}

A 12-year old boy was hospitalized due to short stature: height $128 \mathrm{~cm}(<3$ centile), weight $26.4 \mathrm{~kg}$ ( $<3$ cen- tile). The standard deviation score of height was -4.89 . The patient has suffered from hypothyroidism and hypoparathyroidism since birth. From an interview, we learned that the patient at 3-weeks of age was hospitalized due to convulsions of the right side of the body. Up until the age of 3 , the patient had suffered four times from otitis media. At the age of 6 , the boy had tetany twice after the appearance of vomiting. The patient is substitutionally treated with levothyroxine, calcium, magnesium, and vitamin D.

On the basis of clinical manifestations and biochemical tests such as nocturnal growth hormone secretion, glucagon stimulation test and clonidine test for growth hormone secretion which showed a peak of $\mathrm{GH}<10 \mathrm{ng} / \mathrm{ml}$, the patient was diagnosed with somatotropic hypopituitarism. Accordingly at the age of 6 , the patient was qualified for treatment with growth hormone. During the next two years, the patient had a poor response to the treatment

\section{ADDRESS FOR CORRESPONDENCE:}

Paweł Zapolnik, Students' Scientific Association of Clinical Genetics, Department of Clinical Genetics, Medical

College, University of Rzeszów, 2a Kopisto Ave, 35-959 Rzeszów, Poland, ORCID: 0000-0001-9935-472X,

e-mail: pawel.zapolnik@onet.pl 


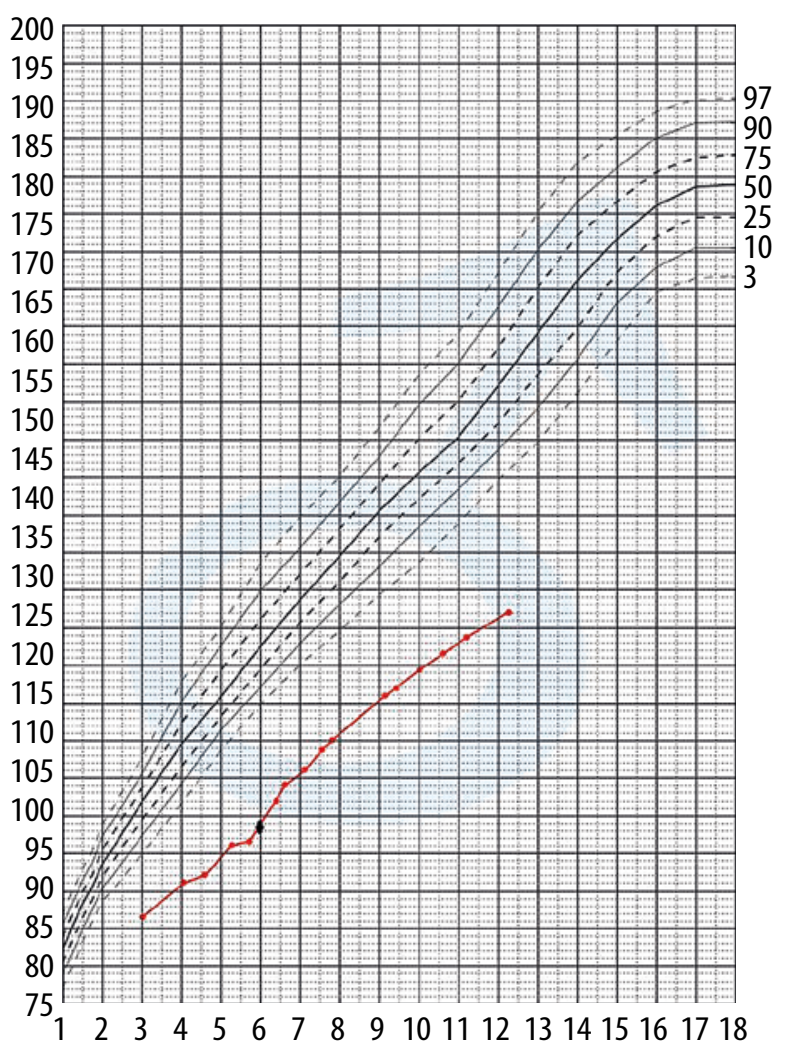

FIGURE 1. The patient's charted growth curve. The black point at the age of six is the beginning of growth hormone therapy

gaining about $2 \mathrm{~cm}$ in height a year and it was decided to have a 3-month therapy break (Fig. 1). After a control check-up and a noticed decrease in the serum level of insulin-like growth factor (80 ng/ml, norm: 143.0-506.0 ng/ $\mathrm{ml})$, it was decided to reinitiate the treatment. A better response to the therapy was observed with a rate of growth approximately $6 \mathrm{~cm}$ per year. Currently, the patient takes

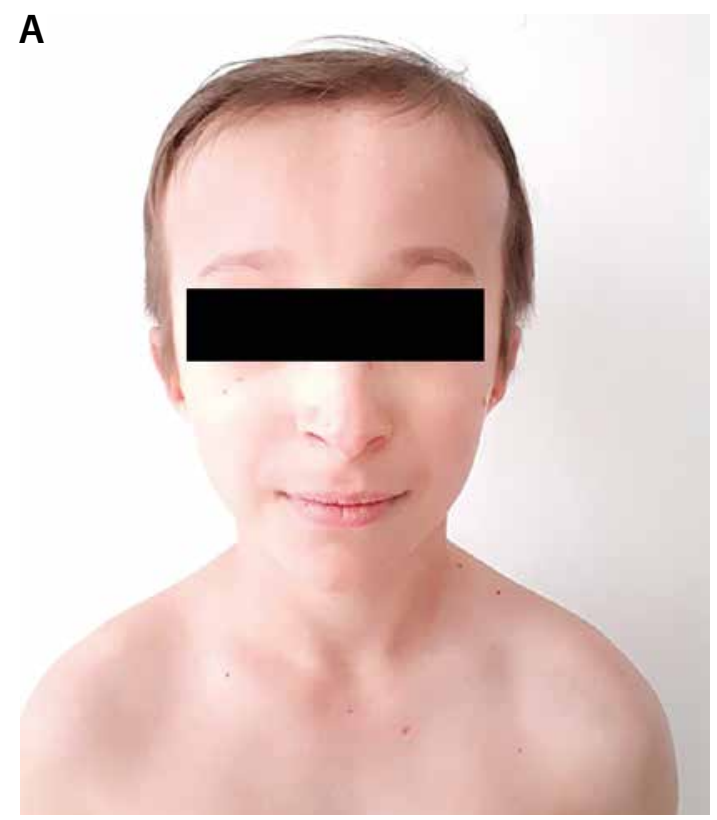

human recombinant growth hormone (somatotropin) at a dose of $5.3 \mathrm{mg} / \mathrm{l}$ per week/16 units per week.

The patient is under the care of a pulmonologist due to bronchial asthma which is controlled without pharmacological substances and a nephrologist due to nocturnal enuresis that was treated for some time with desmopressin without much improvement. The patient has a hearing aid due to bilateral hypoacusis and large hyperopia in both eyes: $+12.0 \mathrm{D}$. The patient's intellectual development is age-appropriate.

During a physical examination, we noted dysmorphic facial features such as deep-set eyes, narrowed palpebral fissures, prominent nose, low set auricles, and prominent frontal bossing (Fig. 2). The anterior $4 \times 4 \mathrm{~cm}$ fontanelle was not closed. The lower limbs are disproportionately shorter in comparison to the torso (Fig. 3). A noticeable feature is also relatively short fingers (Fig. 4). The boy is under constant care of a dentist having deciduous teeth removed because of vast dental caries, and corrective braces. Examination of the genitals showed lack of puberty features. The right testicle with volume of $2-3 \mathrm{ml}$ is located in the scrotum, an undescended left testicle is located by the inguinal canal and the scrotum; a micropenis is also noticeable.

Abnormalities such as hypocalcaemia $(8.3 \mathrm{mg} / \mathrm{dl}$, norm: $8.8-10.6 \mathrm{mg} / \mathrm{dl})$, hyperphosphatemia $(8.2 \mathrm{mg} / \mathrm{dl}$, norm: $4.0-7.0 \mathrm{mg} / \mathrm{dl})$ and a low level of parathyroid hormone (parathormone, PTH) $(7.7 \mathrm{pg} / \mathrm{ml}$, norm: $15-65 \mathrm{pg} / \mathrm{ml}$ ) were detected in performed laboratory tests. The serum level of magnesium and urine levels of calcium and phosphate were normal. Follicle-stimulating hormone, luteinizing hormone, and testosterone were within the referential range. Alkaline phosphatase levels were normal. The assessment of bone age on the

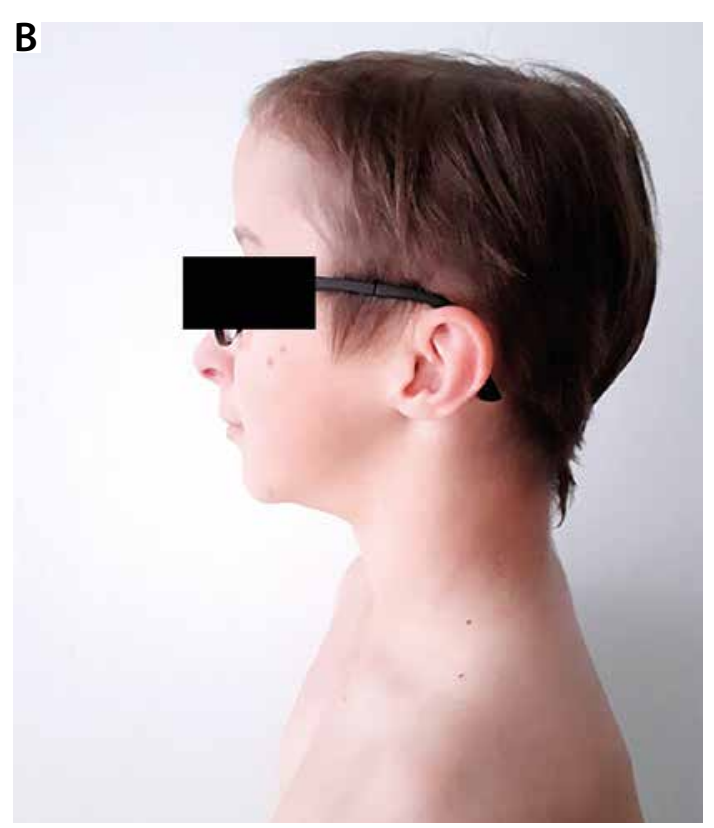

FIGURE 2. The patient at 12 years of age. Deep-set eyes, narrowed palpebral fissures, prominent nose, low set ears, prominent frontal bossing, and low hairline on the back are noticeable 
A

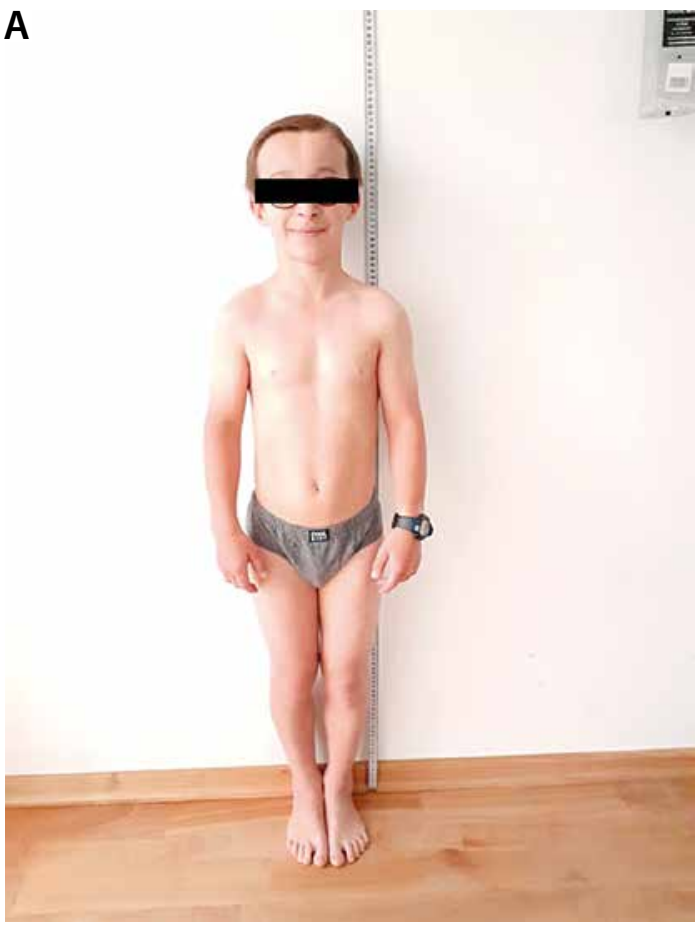

B

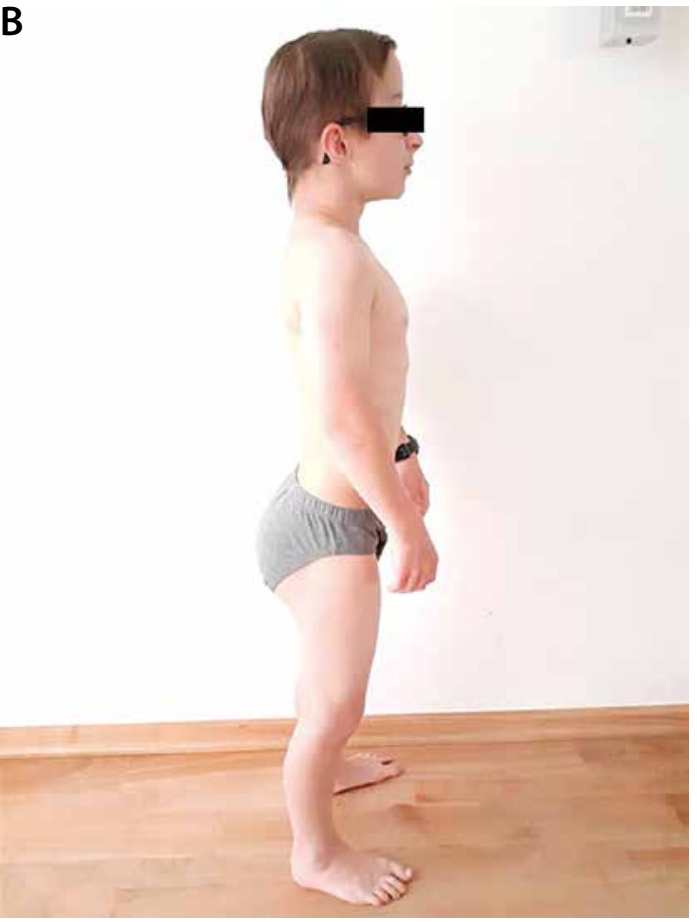

FIGURE 3. The patient is $128 \mathrm{~cm}$ tall. Disproportionately shorter lower limbs draw attention

basis of a wrist X-ray according to Greulich's atlas corresponds to approximately 11 years and 6 months. Figure 5 shows X-ray images. Cerebrum magnetic resonance with contrast was performed and $\mathrm{T}_{1}$-dependent images show a strong signal in the thalamus and also in basal nuclei mainly putamen which probably is connected with abnormalities in calcium and phosphorus balance. The squamous parts of the frontal bones are slightly asymmetrically flat. The diameter of both eyeballs is reduced in a symmetric way to $17 \mathrm{~mm}$ indicating microphthalmia (norm $23 \mathrm{~mm}$ ).

On the basis of clinical manifestation, a pycnodysostosis was suspected and therefore a genetic study was performed. Classical cytogenetic analysis showed a normal male karyotype of 46,XY. As a result of genetic analysis with the use of next-generation sequencing (NGS) technique, the presence of molecular variant c.1706G $>A$ (p.Arg569His, R569H) in one allele of a FAM111A gene was stated. These results confirm the clinical diagnosis of Kenny-Caffey syndrome type 2 because $\mathrm{R} 569 \mathrm{H}$ is a hot spot mutation (frequently mutated) for this disease.

\section{DISCUSSION}

Kenny-Caffey syndrome type 2 is an extremely rare hereditary genetic disorder present in 1 per $1,000,000$ births with the same frequency in both genders [2]. The disorder was first reported by Kenny and Linarelii in 1966 [3] who observed it in the case of a mother and a son. Since then, less than 100 cases of the disorder around the world have been reported [1].

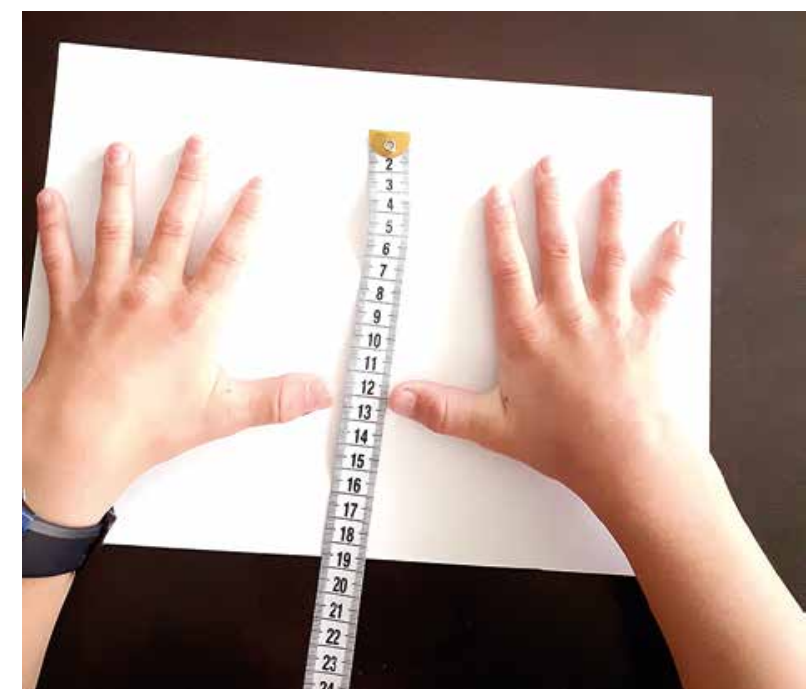

FIGURE 4. Relatively short fingers

The disorder is inherited in an autosomal dominant way and it is connected with a molecular variant of one allele in the FAM111A gene. Mutations happen de novo in some cases. The FAM111A gene encodes a protein consisting of 611 amino acids and its functions are not entirely known. Unger et al. [4] suggested that the gene takes part in skeleton development, parathyroid hormone synthesis, and also in calcium and phosphorus homeostasis.

Clinical manifestation in Kenny-Caffey syndrome type 2 may differ among patients, and particular symptoms appear with changeable frequency. In the prenatal period, intrauterine growth restriction may appear and a low birth weight might be one of the first symptoms. 


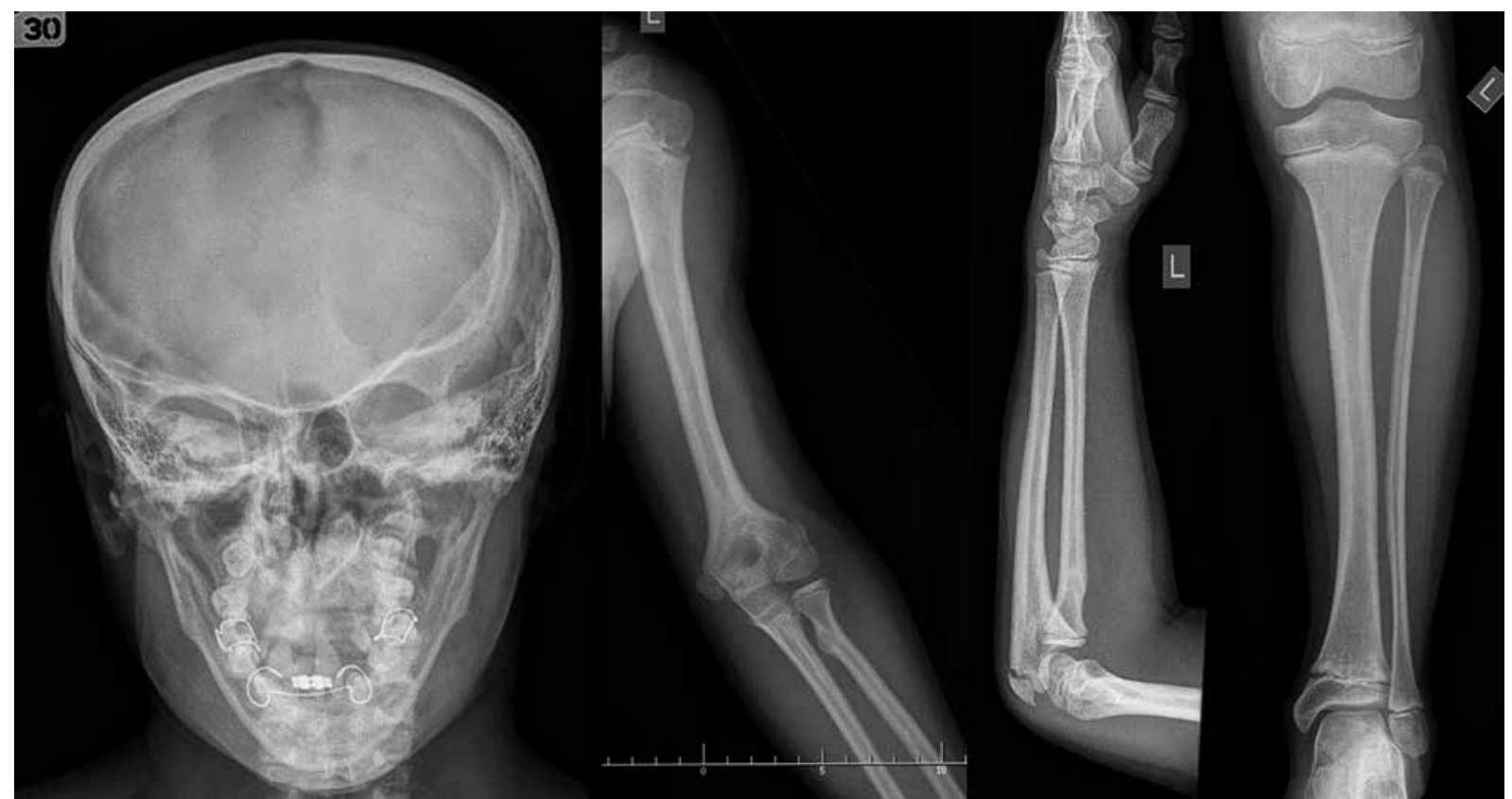

FIGURE 5. X-rays show long bones with reduced medullary space and cortical thickening which are characteristics for Kenny-Caffey syndrome type 2

Abdel-Al et al. [5] compared clinical manifestations in a group of 22 patients with this disorder. Five of 18 cases had a birth weight below $2500 \mathrm{~g}$. The most common feature was a short final height which occurred in 20 of 22 patients, 18 of whom were proportionally short as in the case of our patient, and 2 of the 18 had disproportionately short lower limbs. The final body height among adults varies between $121-149 \mathrm{~cm}$. Similarly, as in the case of our patient, Abraham et al. [6] reported a poor response to treatment with growth hormone.

The other characteristic feature is an abnormality in the skeletal system which was reported in detail by Caffey in 1967 [7]. Abdel-Al et al. [5] reports that skeletal disorders are present in $80-90 \%$ of patients and most commonly involves delayed closure of the anterior fontanelle which should normally close by 18 months after birth and may remain open even until adolescence as in the case of our patient. Delayed closure of the anterior fontanelle is one of the most characteristic features of Kenny-Caffey syndrome type 2 . Cranial sutures may also close late. In $60 \%$ of patients, delayed bone age is observed which was confirmed in the case of our patient on the basis of wrist $\mathrm{X}$-ray. Cortical thickening and medullary stenosis of long bones are equally frequent (Fig. 5). In some cases, osteosclerosis may appear $[8,9]$. Skeletal changes may be noticed in radiologic studies [1].

Among patients suffering from the disorder, one notices dysmorphic facial features, such as macrocephaly with prominent frontal bossing and hypertelorism with microphthalmia as well as small hands and feet, which was observed in the case of our patient. In some patients, hypoplastic nails may appear [8]. Despite multiple dysmorphic features, intellectual development is usually age-appropriate and the milestones in the child's development are achieved in proper time [8].

Kenny-Caffey syndrome type 2 is also a rare cause of hypoparathyroidism, which is usually transient and remittent. Abdel-Al et al. [5] stated that 16 of 22 patients suffered from hypocalcemia, 13 of whom had tetany as in the case of our patient. Disorders in the form of general tetany seizures may appear in the first months of life as well as later in life. Other symptoms resulting from electrolyte imbalances are: muscle tremors, stridor, long exhalation, hyperesthesia, feeding problems in babies, and vomiting due to pyloric spasm. In case of older children, these are: neuromuscular hyperactivity such as paraesthesia, and muscle spasm. Laryngospasm and asthma attacks may also appear $[8,10]$. As in the case of our patient, in over $60 \%$ of cases reported by Abdel-Al et al. [5] there was hyperphosphatemia and there was decreased parathyroid hormone secretion in $30 \%$ of patients. In all patients, as well as in the case of our patient, alkaline phosphatase level was normal. Chronic hypoparathyroidism leads to the appearance of formation calcified basal ganglia which was observed by X-ray and may be connected with mental disorders in the future (depression, anxiety) as well as neurological disorders (epilepsy) [11].

Thyroid gland function was noted among 9 patients in the literature review by Abdel-Al and others [5]. In all cases, thyroid hormones were normal in contrary to our patient who suffers from hypothyroidism. Currently, it is effectively treated with levothyroxine and hormone levels are normal. This shows that hypothyroidism is not a characteristic of Kenny-Caffey syndrome type 2 and is not commonly searched for in patients. 
There are also different clinical features in KennyCaffey syndrome type 2 concerning development disorders in various organs.

Isojima et al. [12] reported the presence of reappearing otitis media in early childhood, which also appeared in the case of our patient. In the literature, we have also found problems associated with teeth in patients suffering from Kenny-Caffey syndrome type 2 [13]. There could be enamel hypoplasia, oligodontia, short roots, and an increased risk of dental caries which, in the case of our patient, led to the necessity of tooth removal.

Abnormalities in Kenny-Caffey syndrome type 2 also occur in eyes. In 1979, Boynton et al. [14] reported mainly cases of large hyperopia which usually appeared together with abnormally small eyeballs as in the case of our patient. Microphthalmia may also be a cause for the appearance of angle-closure glaucoma. There are also cases of myopia, bilateral optic atrophy, strabismus, corneal and retinal calcification. In some cases, there is also apparent papilledema. Enriquez et al. [15] reported a case of a 6-year old girl who suffered from bilateral congenital cataracts. In the examination of the fundus of the eye, the optic disc was elevated and swollen with tortuous and dilated retinal vessels.

Abdel-Al et al. [5] reported anaemia in only 5 patients out of 16 . There was no connection between medullary stenosis of long bones and anaemia. Anaemia is not common in Kenny-Caffey syndrome type 2, and we also did not find this abnormality in our patient.

Hoffman et al. [16] reported on the cases of two boys suffering from Kenny-Caffey syndrome type 2; both patients as well as our patient had microorchidism. One of them had an increased FSH level while the levels of LH and testosterone were normal; in case of the other boy the level of gonadal hormones was normal. In men, follicle-stimulating hormone is responsible for maturation of testicles as well as the regulation of spermatogenesis through an influence on Sertoli cells. The high level of the hormone suggests male hypogonadism and also infertility [11]. A cause of infertility in Kenny-Caffey syndrome type 2 has not been suggested overall [8].

Our patient has most of the characteristic features of Kenny-Caffey syndrome type 2 . A summary and comparison of the clinical features of our patient with other cases is provided in Table 1 .

Detection of a mutation in the FAM111A gene is needed to confirm the diagnosis. Currently, the best method to detect mutation is NGS. If the patient has an undiagnosed developmental delay or intellectual disability and dysmorphic features, it is advisable to initiate diagnostics recommended by the American Society of $\mathrm{Hu}$ man Genetics [17]. In such cases, it is worth performing a microarray-based comparative genomic hybridization (aCGH) test before or simultaneously with NGS.

In differential diagnosis, the autosomal recessive form of the disease, Kenny-Caffey syndrome type 1, needs to
TABLE 1. Clinical features of our patient compared to the literature reports $[5,7,8,12-15]$

\begin{tabular}{|l|c|}
\hline Feature & Our patient \\
\hline Short stature & + \\
\hline Prominent forehead & + \\
\hline Eye abnormalities & + \\
\hline Defective dentition & + \\
\hline Microorchidism & + \\
\hline Thickened cortex of long bones & + \\
\hline Dense tubular bones and narrow marrow cavities & + \\
\hline Delayed closure of anterior fontanel & + \\
\hline Normal intelligence & + \\
\hline Tetany & + \\
\hline Basal ganglia calcification & + \\
\hline Seizures & - \\
\hline Low parathyroid hormone level & + \\
\hline Anaemia & - \\
\hline Hypocalcaemia & + \\
\hline Hyperphosphatemia & + \\
\hline
\end{tabular}

be taken into consideration which in contrast to the autosomal dominant entity proceeds with mental disability. Differential diagnostics should include osteochondrodysplasias with osteopetrosis like autosomal recessive osteopetrosis, pycnodysostosis, cleidocranial dysplasia as well as Lenz-Majewski syndrome [1]. The patient was initially suspected of pycnodysostosis. Clinical features such as short stature, osteosclerotic lesions in bones, frontal bossing, persistent open anterior fontanelle could indicate this diagnosis. Pycnodysostosis, however, has several features that distinguish this unit from Kenny-Caffey syndrome type 2 . These are the following characteristics: micrognathia, hypoplasia/aplasia of clavicles, Wormian bones, scoliosis, flattened and grooved nails. It is crucial for clinicians to carefully check all of these features and make a correct suspicion, which might help in further diagnostics. Molecular testing with gene panel or WES is essential to make a definitive diagnosis.

Treatment of Kenny-Caffey syndrome type 2 is only symptomatic. It is important to perform laboratory tests regularly with special attention to parathyroid gland functions. In order to level the calcium and phosphorus economy, calcium and vitamin D need to be supplemented. In the case of anaemia, iron is used. One needs to remember that patients should be kept under the strict care of ophthalmologist due to a large amount of eye abnormalities and congenital cataract surgery is required [1]. It is also advisable to provide special dental hygiene and regular dental check-ups [13]. 


\section{CONCLUSIONS}

Kenny-Caffey syndrome type 2 is a very rare disorder that may manifest in a heterogeneous way. A short stature, hypoparathyroidism, abnormalities in the skeletal system and eyes should alert physicians. The proper method to confirm the diagnosis is next-generation sequencing. Due to the lack of causal treatment, patients with Kenny-Caffey syndrome type 2 should remain under interdisciplinary care.

\section{ACKNOWLEDGMENT}

We would like to thank doctor David Aebisher for his help in revising the text.

\section{DISCLOSURE}

The authors declare no conflict of interest.

\section{REFERENCES}

1. National Organization for Rare Disorders. Kenny-Caffey Syndrome. 2012. https://rarediseases.org/rare-diseases/kenny-caffey-syndrome/ (access: 15.05.2020).

2. Orphanet. https://www.orpha.net/consor/cgi-bin/OC_Exp.php?1ng=EN\&Expert=2333 (access: 14.05.2020).

3. Kenny FM, Linarelli L. Dwarfism and cortical thickening of tubular bones. Transient hypocalcemia in a mother and son. Am J Dis Child 1966; 111: 201-207.

4. Unger S, Górna MW, Le Béchec A, et al. FAM111A mutations result in hypoparathyroidism and impaired skeletal development. Am J Hum Genet 2013; 92: 990-995.

5. Abdel-Al YK, Auger LT, el-Gharbawy F. Kenny-Caffey syndrome. Case report and literature review. Clin Pediatr (Phila) 1989; 28: 175-179.

6. Abraham MB, Li D, Tang D, et al. Short stature and hypoparathyroidism in a child with Kenny-Caffey syndrome type 2 due to a novel mutation in FAM111A gene. Int J Pediatr Endocrinol 2017; 2017: 1.

7. Caffey J. Congenital stenosis of medullary spaces in tubular bones and calvaria in two proportionate dwarfs--mother and son; coupled with transitory hypocalcemic tetany. Am J Roentgenol Radium Ther Nucl Med 1967; 100: 1-11.

8. Online Mendelian Inheritance in Man. http://www.omim.org/entry/127000. Last edited 06/02/2017 (access: 14.05.2020).

9. Bove-Fenderson E, Mannstadt M. Hypocalcemic disorders. Best Pract Res Clin Endocrinol Metab 2018; 32: 639-656.

10. Majewski F, Rosendahl W, Ranke M, et al. The Kenny syndrome, a rare type of growth deficiency with tubular stenosis, transient hypoparathyroidism and anomalies of refraction. Eur J Pediatr 1981; 136: 21-30.

11. Pyrżak B, Walczak M. Endokrynologia wieku rozwojowego. PZWL Wydawnictwo Lekarskie, Warszawa 2018.

12. Isojima $\mathrm{T}$, Doi K, Mitsui J, et al. A recurrent de novo FAM111A mutation causes Kenny-Caffey syndrome type 2. J Bone Miner Res 2014; 29: 992-998.

13. Moussaid Y, Griffiths D, Richard B, et al. Oral manifestations of patients with Kenny-Caffey Syndrome. Eur J Med Gen 2012; 55: 441-445.
14. Boynton JR, Pheasant TR, Johnson BL, et al. Ocular findings in Kenny's syndrome. Arch Ophthalmol 1979; 97: 896-900.

15. Enriquez EJ, Toledo F, Bustamante-Cruz M, et al. Congenital medullary tubular stenosis. A case report of Caffey-Kenny syndrome. Acta Orthop Scand 1988; 59: 326-327.

16. Hoffman WH, Kovacs K, Li S, et al. Kenny-Caffey syndrome and microorchidism. Am J Med Genet 1998; 80: 107-111.

17. Miller DT, Adam MP, Aradhya S, et al. Consensus statement: chromosomal microarray is a first-tier clinical diagnostic test for individuals with developmental disabilities or congenital anomalies. Am J Hum Genet 2010; 86: 749-764. 